\title{
The Predatory Mite Phytoseiulus persimilis Does Not Perceive Odor Mixtures As Strictly Elemental Objects
}

\author{
Michiel van Wijk • Paulien J. A. de Bruijn • \\ Maurice W. Sabelis
}

Received: 3 November 2009 /Revised: 12 August 2010 /Accepted: 3 September 2010 /Published online: 25 September 2010

(C) The Author(s) 2010. This article is published with open access at Springerlink.com

\begin{abstract}
Phytoseiulus persimilis is a predatory mite that in absence of vision relies on the detection of herbivoreinduced plant odors to locate its prey, the two-spotted spider-mite Tetranychus urticae. This herbivorous prey is feeding on leaves of a wide variety of plant species in different families. The predatory mites respond to numerous structurally different compounds. However, typical spidermite induced plant compounds do not attract more predatory mites than plant compounds not associated with prey. Because the mites are sensitive to many compounds, components of odor mixtures may affect each other's perception. Although the response to pure compounds has been well documented, little is known how interactions among compounds affect the response to odor mixtures. We assessed the relation between the mites' responses elicited by simple mixtures of two compounds and by the single components of these mixtures. The preference for the mixture was compared to predictions under three conceptual models, each based on one of the following assumptions: (1) the responses elicited by each of the individual components can be added to each other; (2) they can be averaged; or (3) one response overshadows the other. The observed response differed significantly from the response predicted under the additive response, average response, and overshadowing response model in 52,36 , and $32 \%$ of the experimental tests, respectively. Moreover, the behav-
\end{abstract}

Electronic supplementary material The online version of this article (doi:10.1007/s10886-010-9858-3) contains supplementary material, which is available to authorized users.

M. van Wijk $(\varangle) \cdot$ P. J. A. de Bruijn $\cdot$ M. W. Sabelis Institute for Biodiversity and Ecosystem Dynamics (IBED), Section Population Biology, University of Amsterdam,

Science Park 904,

1090 GE Amsterdam, The Netherlands

e-mail: M.vanWijk@uva.nl ioral responses elicited by individual compounds and their binary mixtures were determined as a function of the odor concentration. The relative contribution of each component to the behavioral response elicited by the mixture varied with the odor concentration, even though the ratio of both compounds in the mixture was kept constant. Our experiments revealed that compounds that elicited no response had an effect on the response elicited by binary mixtures that they were part of. The results are not consistent with the hypothesis that $P$. persimilis perceives odor mixtures as a collection of strictly elemental objects. They suggest that odor mixtures rather are perceived as one synthetic whole.

Key Words Olfaction - Synthetic odor perception . Odor mixtures $\cdot$ Binary mixture $\cdot$ Mite $\cdot$ Learning . Herbivore-induced plant volatiles

\section{Introduction}

Upon attack by herbivorous mites, plants attract predatory mites by changing the composition of the odor they emit (Dicke et al., 1998; Sabelis et al., 1999). These odors consist of a complex mixture of herbivore-induced and noninduced plant compounds. Predators use this complex chemical signal to locate herbivore-infested plants in an equally complex odor background produced by other (possibly herbivore-infested) plants (Schröder and Hilker, 2008). It is not known to what extent predatory mites perceive odor mixtures by their individual components (here referred to also as molecular elements or elemental objects) or as a synthetic whole. Consequently, it is not clear if individual herbivore-induced compounds are the key mediators of predatory mite attraction, or if the mites 
are instead attracted to the mixture as a whole. Here, we seek to disentangle these alternatives.

In the present study, we investigated the behavioral response of the predatory mite Phytoseiulus persimilis to individual volatile compounds and to binary mixtures thereof. This predatory mite feeds on the highly polyphagous two-spotted spider-mite Tetranychus urticae (Bolland et al., 1998). The predatory mite relies entirely on olfactory cues to locate distant spider-mite-infested plants (Sabelis and Van der Baan, 1983; Sabelis et al., 1984; Dicke et al., 1990; Dicke and Dijkman, 1992). Different plants produce qualitatively and quantitatively different odor mixtures in response to spider-mite feeding (van den Boom et al., 2004). Consistent with the chemical diversity of the information associated with its prey this predatory mite responds to a wide variety of spider-mite induced plant odor mixtures (van den Boom et al., 2002) and a wide range of structurally different volatile compounds (Dicke et al., 1990; de Boer and Dicke, 2004a, b; Kappers et al., 2005; van Wijk et al., 2008). Discriminating the odor of a spider-mite-infested plant from an uninfested conspecific is a challenging task because many components of both odor mixtures will be present in both. Spider-mite-infested tomato, for example, emits substantial amounts of 19 compounds, 5 of which change significantly in concentration after spider-mite infestation.

Discrimination of the target odor from similar odor sources essentially can be achieved in two ways. Odor perception could be elemental, i.e., the mites perceive and respond to individual components of the mixture. As the components in a mixture are recognized, a component that is an attractant when presented individually is also in a mixture recognized as an attractant. Hence, if odor perception is elemental, the additive effects of all individually recognized attractants and repellents in the mixture will form a likely estimate of the attraction to the mixture. However, in most olfactory systems, the different chemical components of odor mixtures are not detected as independent elements because different odorants of the same mixture may compete for the same receptor site (Oka et al., 2004; Rospars et al., 2008), or because they may affect each other's representation through cross-glomerular circuit interactions in the olfactory system (Kay and Stopfer, 2006; Riffell et al., 2009). Consequently, odor perception becomes synthetic, the individual components of a blend may no longer be recognizable in the mixture, and the mixture is perceived as a distinct odor different from its individual components. This may facilitate the ability to discriminate between mixtures that share many components such as the odor of herbivore-infested plants and uninfested conspecifics. This is because synthetic perception releases the brain from the constraint of representing an odor in the same way, whether it is part of a mixture or not. Hence, correlated olfactory input can be decorrelated in such a way, that the ensemble of neurons encoding one odor, shares little or no overlap with the ensemble of neurons encoding the other. Consequently, when olfaction is strictly synthetic, the response elicited by a specific volatile compound may be entirely different from its contribution to the response elicited by a mixture that it is part of.

The central nervous system of Phytoseiulus persimilis consists of just 10.000 cells (van Wijk et al., 2006a). Its glomerular olfactory system is similar to the system found in insects and vertebrates (van Wijk et al., 2006b). The relative simplicity of this mite's olfactory system combined with its reliance on olfaction to locate distant prey makes it an ideal model organism to study how predators utilize the complex and variable source of olfactory information that herbivore- infested plants provide.

The olfactory response elicited by the individual components of an odor mixture serve as the input for three conceptual models that are used to predict the response elicited by the mixture. These model predictions were compared to the observed response elicited by the binary mixture in the predatory mite $P$. persimilis.

(1) One model is additive and therefore tests the assumption that the response elicited by each of the mixture's components contribute equally to the response elicited by the mixture.

(2) In a second model, the response elicited by an odor mixture is equal to the response elicited by the mixture's component that elicits the strongest response. Hence, this model is consistent with the frequently observed phenomenon of overshadowing, i.e., an olfactory system that receives competitive inputs by the different chemical components in the odor mixture. The odor that elicits the strongest response inhibits the perception of or the response to the other components in the mixture.

(3) The third model is intermediate between the other two models. Here, we assume that the response to a mixture is equal to the mean response elicited by its components. Hence, it is assumed that all of the mixture's components contribute equally to the response elicited by the mixture, while the perception of or the response to each component is reduced by the fraction of the total number of components in the mixture.

Because odors occur at different concentrations, we do not only investigate how the different components of odor mixtures affect the response that these mixtures elicit, but also, whether the same mechanism applies at different concentrations of the same odor mixture. This was examined in a separate series of experiments where we asked if a function that describes the response to a binary mixture as a function of the response to its components at 
one concentration also describes the response to the same mixture at other concentrations.

\section{Methods and Materials}

Plants and Mites Lima been plants (Phaseolus lunatus) were grown from seeds in a climate room $\left(22^{\circ} \mathrm{C}, 60 \% \mathrm{RH}\right.$, 16:8 LD). After 2 week, these plants were infested with two spotted spider-mites (Tetranychus urticae Koch) to establish a culture of this mite. Predatory mites (Phytoseiulus persimilis Athias-Henriot) were reared in a climate room $\left(25^{\circ} \mathrm{C}, 60 \% \mathrm{RH}, 16: 8 \mathrm{hL}: \mathrm{D}\right)$ on detached, spider-miteinfested Lima bean leaves. The predatory mites received fresh, spider-mite-infested Lima bean leaves every day, and the culture was harvested every day except for the weekend. This frequent harvesting of adult female mites ensured that most mites used in the experiments were one to a few days old after their molt to the adult phase. Predatory mites were obtained originally in 2001 from various locations near the coast of Sicily, Italy. Before choice tests, female predatory mites were kept in Eppendorf tubes and were deprived of water and food for 16-22 hr.

Odor Odors were selected from a panel of pure volatile compounds used to assess the olfactory response of $P$. persimilis (van Wijk et al., 2008). The odors selected for this study ensure that all possible combinations of repellents, attractants, and odors that elicited no response could be made. Most odors were obtained from Fluka with the exception of 2,3-dimethyl pyrazine that was obtained from Aldrich. Octan-1-ol and butan-1-ol were obtained from Sigma, dodecyl acetate from Aldrich, methyl salicylate (MeSA) from Sigma-Aldrich, and $\beta$-ocimene $(70 \% E$ - and $30 \% Z$ - isomers) from R. C. Treat \& co. The terpenoids $(E)$ 4,8-dimethyl-1,3,7-nonatriene (DMNT) and (E,E)-4,8,12trimethyl-1,3,7,11-tridecatetraene (TMTT) were provided by Dr. W. Boland of the Max Planck Institute for Chemical Ecology, Jena, Germany.

Olfactory Response Tests Choice tests were conducted as described by van Wijk et al. (2008). In short, the response to the odors was assessed by using an experimental arena constructed from a Petri dish (diam $9 \mathrm{~cm}$ ) positioned upside down. A radial airflow was established by the connection of a vacuum pump (flow $0.42 \mathrm{l} / \mathrm{min}$ ) to an opening at the center of the bottom (lid) of the Petri dish. Prior to the experiment, groups of about 25 predatory mites were placed in cartridges that could be fitted between the vacuum pump and the experimental arena. For each replicate, the arena was provided with fresh odor sources and a new cartridge with a new group of predatory mites. Each odor was tested in a different set-up. To restrain predatory mites after their choice on each side of the arena, an insect glue barrier divided the arena into two halves except for an opening of $3 \mathrm{~cm}$ at the center of the bottom of the arena. This opening allowed mites to move from the cartridge to the side of their choice, and it allowed mites to move from one side to the other. One side contained filter paper (diam. $1 \mathrm{~cm}$ ) with $0.5 \mu \mathrm{l}$ of the odor (dissolved in hexane), and the other side contained a control filter paper with $0.5 \mu$ l of the solvent (hexane). Odor sources were prepared in a fume hut, and the solvent was allowed to evaporate for $1 \mathrm{~min}$ before the odor source was placed in the set-up. Mites were released from the cartridge, and after $3 \mathrm{~min}$ the mites at both halves of the choice dish were counted.

Control Experiments To assess whether there is a difference between the measured olfactory preference of $P$. persimilis released in groups and $P$. persimilis released individually, a control experiment was conducted. In this experiment, the olfactory preferences of mites released individually (40 mites) and mites released in groups (six groups each with ca. 20 individuals) were compared. Four different combinations were tested: 1) no odor at both sides of the Petridish; 2) a Lima bean leaf discs (1,5 cm) vs. no odor at the control side; 3) a leaf disc at both sides; 4) a spider-mite infested leaf disc (web, eggs and mites removed) vs. an uninfested leaf disc.

Experimental Design and Statistics The preference of nine groups, each consisting of ca. 25 mites was tested for each of the two odors and their binary mixture. The experimental design followed a $3 \times 3$ Latin square; the odors $(A, B$, and the mixture $\mathrm{AB}$ ) formed one side of the square while the other consisted of the experimental sequence. Hence, each odor was perceived by three groups first, by three groups second, and so on, thereby ensuring that three clusters of three groups of ca. 25 mites received the three odors in three different sequences. All experiments in one Latin square were completed in ca. $75 \mathrm{~min}$. The mites were held ca. 20 min. in Eppendorf tubes between subsequent choice tests.

Assuming individual mites make independent choices, the response to each of the three odors compared to the control was analyzed using the replicated $G$-test for goodness of fit (Sokal and Rohlf, 1995). Differences among choice experiments were determined by analysis of variance (ANOVA) of the arcsine square root transformed frequencies of the olfactory preference, followed by Bonferroni post-hoc testing. This not only allowed us to test if there was a difference between the responses to the odors, but also if there was an effect of the position in the sequence and whether there was a difference among the experimental sequences as a whole. 
The experimental results were compared to three model predictions. These models predict the response that a binary mixture elicits as a function of the response to each of the mixture's components. The first model had the following additive structure:

$\mathrm{E}_{(\mathrm{AB})}=\left(0.5+\left(\mathrm{O}_{(\mathrm{A})}-0.5\right)+\left(\mathrm{O}_{(\mathrm{B})}-0.5\right)\right) * 100 \%$

Here, $\mathrm{E}_{(\mathrm{AB})}$ is the expected attraction to the mixture $\mathrm{AB}$ in $\%$, and $\mathrm{O}_{(\mathrm{A})}$ and $\mathrm{O}_{(\mathrm{B})}$ are the observed fractions of mites attracted to odor $\mathrm{A}$ and $\mathrm{B}$, respectively. If $\mathrm{E}_{(\mathrm{AB})}$ became greater than $100 \%$, it was assumed to be $100 \%$. Under the second model, it was assumed that the response that a mixture elicits was equal to the response elicited by the mixture's component that elicited the strongest response. Hence, there is always a complete overshadowing. Under the third model, the expected response elicited by the binary mixture was predicted to be equal to the mean of the response elicited by its components $\left[\left(\mathrm{E}_{(\mathrm{AB})}=\left(\left(\mathrm{O}_{(\mathrm{A})+} \mathrm{O}_{(\mathrm{B})}\right) / 2 * 100 \%\right)\right]\right.$. The observed attraction to the binary mixture was compared to the expected attraction under each of the three models using a $X^{2}$ for goodness of fit test.

Binary Mixtures with the Same Component Ratio at Different Concentrations Dose response curves (pure odor, 10, 100, and 1000 times diluted odor in hexane) were generated in a way similar to the experiments described by van Wijk et al. (2008). The response to each concentration of each odor was tested in 6 replicate experiments, each based on ca. 20 predatory mites. Dose response curves for the binary mixtures described here were measured simultaneously with the dose response curves for their components published earlier (Van Wijk et al., 2008).

\section{Results}

Control Experiments To examine if $P$. persimilis mites released in groups show the same preference for odors in the experimental set-up as $P$. persimilis released individually, 4 control experiments were conducted. The olfactory responses by $P$. persimilis assayed in groups did not differ from those tested individually (Table 1).

To examine whether the repetitive testing affected the responsiveness of the mites, a meta-analysis was performed on all experiments listed in Table 2. We regressed the responsiveness defined as absolute fraction of mites attracted to each odor minus 0.5 , on the position in the experimental sequence. We found that the responsiveness did not vary with the position in the experimental sequence (equation of the regression line: $y=-0.0017 x+0.1244$, $r^{2}=0.0002$ with $\mathrm{y}$ being the responsiveness and $\mathrm{x}$ being the position in the experimental sequence). Additionally, we checked for each experiment whether there were differences among the different experimental sequences and among the positions of odors in the experimental sequence using ANOVA on the arcsine square root transformed frequencies of the olfactory preference followed by Bonferroni post-hoc analysis (Supplemental data Table 1). We did not detect any effect of the sequential testing on the olfactory preference except for experiment 1 ( $\alpha$-humulene and linalool). In this experiment, a significant effect of the position in the experimental sequence was found. This was due to the significant heterogeneity in the response to $\alpha$ humulene (Table 2). In 9 choice tests (three times as the first, the second, and the third odor in the sequence), significant repellence was measured only once, when the odor was presented as the first odor in the sequence. Significant attraction was measured twice, when the odor was presented as the third odor in the sequence. The other six replicates revealed neither attraction nor repellence.

The Contribution of Each Component to the Mixture's Attractiveness We investigated the response of $P$. persimilis to 25 binary mixtures and to their individual components. Table 2 reports the fraction of mites $(9$ replicate experiments of ca. 25 mites per mixture) that were attracted to each binary mixture and its components. Table 2 also reports the predicted response under each of the proposed models, i.e., the additive response, the averaged response, and the overshadowing response model.

Based on the response to the mixtures' components, the experimental results can be divided into three groups: (1) experiments in which both components did not elicit a significant choice $\left(G_{p}{ }^{n s}\right)$ (experiment 1 to 7, Table 2); (2) experiments in which one of the components elicited a response $\left(G_{p}{ }^{*}\right)$ whereas the other did not (experiment 8 to 17, Table 2); and (3) experiments in which both components elicited a response $\left(G_{p}{ }^{*}\right)$ (experiment 18 to 25 , Table 2). Figure 1 depicts the difference between the observed attraction to each binary mixture and the predicted attraction under each of the models.

In experiment 1 to 7 both components of the mixture elicited no response. Hence, in these experiments, the averaged response model and the overshadowing response model predict no significant attraction to or repellence of the mixture. Likewise, the additive response model predicts no response except when the response that each odor elicits borders significance and has the same direction. This latter case explains the significant difference between the observed absence of a response $\left(G_{p}{ }^{n s}\right)$ for the mixture and the expected response under the additive response model in experiments 2 (octan-1-ol and TMTT) and 5 (farnesol and 
Table 1 Olfactory preference measured with mites released in groups and mites released individually

\begin{tabular}{|c|c|c|c|c|c|c|c|c|c|c|c|c|}
\hline \multirow{2}{*}{$\begin{array}{l}\text { Group/ } \\
\text { individual }\end{array}$} & \multirow[t]{2}{*}{ No odor $(\%)$} & \multirow[t]{2}{*}{ No Odor $(\%)$} & \multicolumn{7}{|c|}{ Replicated $G$-test for goodness of fit } & \multicolumn{2}{|l|}{$G$-test } & \multirow{2}{*}{$\begin{array}{l}\text { Difference between } \\
\text { mites released in groups } \\
\text { and mites released } \\
\text { individually }(\chi 2 \text { test }) \\
P(\chi 2) \text { d.f. }=1\end{array}$} \\
\hline & & & $N$ & $G_{p}$ & $\begin{array}{l}P\left(G_{p}\right) \\
d . f .=1\end{array}$ & $\mathrm{G}_{\mathrm{h}}$ & $\begin{array}{l}P\left(G_{h}\right) \\
d . f .=5\end{array}$ & $\mathrm{G}_{\mathrm{t}}$ & $\begin{array}{l}P\left(G_{t}\right) \\
\text { d.f. }=6\end{array}$ & $G$ & $\begin{array}{l}P(G) \\
d . f .=1\end{array}$ & \\
\hline 6 groups & 47.64 & 52.45 & 118 & 0.08 & 0.78 & 2.81 & 0.73 & 2.89 & 0.82 & & & \\
\hline Individuals & $\begin{array}{l}42.50 \\
\text { Leaf disc }(\%)\end{array}$ & $\begin{array}{l}57.50 \\
\text { Leaf disc }(\%)\end{array}$ & 40 & & & & & & & 0.90 & 0.34 & 0.28 \\
\hline 6 groups & 48.74 & 51.26 & 119 & 0.08 & 0.78 & 2.81 & 0.73 & 2.89 & 0.82 & & & \\
\hline Individuals & $\begin{array}{l}52.50 \\
\text { Leaf disc }(\%)\end{array}$ & $\begin{array}{l}47.50 \\
\text { No odor }(\%)\end{array}$ & 40 & & & & & & & 0.10 & 0.75 & 0.41 \\
\hline 6 groups & 52.54 & 47.46 & 118 & 0.31 & 0.58 & 5.21 & 0.39 & 5.52 & 0.48 & & & \\
\hline Individuals & $\begin{array}{l}45.00 \\
\text { Infested leaf disc (\%) }\end{array}$ & $\begin{array}{l}55.00 \\
\text { Leaf disc }(\%)\end{array}$ & 40 & & & & & & & 0.40 & 0.53 & 0.10 \\
\hline 6 groups & 79.00 & 21.00 & 119 & 42.62 & 0.00 & 6.82 & 0.23 & 49.44 & 0.00 & & & \\
\hline Individuals & 80.00 & 20.00 & 40 & & & & & & & 15.42 & 0.00 & 0.78 \\
\hline
\end{tabular}

dodecyl acetate) (Fig. 1). The significant response to the mixtures $\left(G_{p}{ }^{*}\right)$ in experiment 3 (dodecyl acetate, and 2,3dimethyl pyrazine) and 6 (hexyl acetate and cis-3-hexen-1ol) was significantly different from the predicted response under all three models. Given the variances among replicates, this does not necessarily imply that the difference among the components and the mixture differ significantly. As the experimental design followed a $3 \times 3$ Latin square, differences among odors were determined by analysis of variance ( $A N O V A)$. In this $A N O V A$, the arcsine square root transformed frequencies of the 27 individual choice experiments were analyzed for significant differences among the response to odors, position in the experimental sequence, and the three groups of different experimental sequences in the experiment. This analysis revealed that there were significant differences between the odors in experiment $6\left(F_{2}=4.33, P<0.05\right)$ and in experiment $3\left(F_{2}=18,34, P<0.05\right)$. Post hoc analysis revealed that the response to the mixture was significantly different from the response to its individual components. Hence, we conclude that in these experiments a mixture of two compounds that individually elicited no response, elicited a response when blended together in a binary mixture.

In experiment 8 to 16 , one component of the binary mixture elicited no response whereas the other did. The overshadowing response model predicts that the response to the mixture is equal to the response elicited by the mixture's component that elicited a response. The additive response model predicts a response similar to that. Only the response to the mixture in experiment 8 ( $\alpha$-pinene and cis3-hexen-1-ol) was significantly different from that predicted by the overshadowing response model. Experiments
8, 10 (dodecyl acetate and octan-1-ol) and 16 (linalool and MeSA) revealed a significant difference between the observed and the predicted response under the additive response model. In experiment 16 , this appears to result from the fact that the repellence by the mixture was greater than the additive repellence by its components. ANOVA and the subsequent post hoc analysis revealed that this difference tended to be significant at $P=0.07, d . f .=6$. The reverse is seen in experiments 8 and 10 . Here, the mixture elicited no response $\left(G_{p}{ }^{n s}\right)$ whereas one of its components did $\left(G_{p}{ }^{*}\right)$. The ANOVA revealed that in both experiments the response to the mixture was not significantly different from the response to its components. Hence, although the responses to the mixture and its components were not significantly different, the replicated $G$-test indicates that the mites made no choice when provided with the mixture, whereas they did when offered one of its components. Moreover, the observed response in experiment 8 was significantly different from both the overshadowed response and the additive response model. In conclusion, in experiments in which only one of the mixtures' components elicited a response, the two models that predict overshadowing for the response to the mixture are most consistent with the observed response. There are, however, several cases where the component that elicited no response contributed to the response elicited by the binary mixture (experiment 8, 10, and 16).

In the last group of experiments, components in each mixture elicited a response. As in the previous groups of experiments, none of the models accurately predicts the response to all binary mixtures in this group. On one side of the spectrum, there are cases of overshadowing by the 


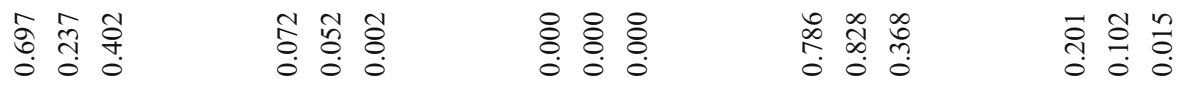

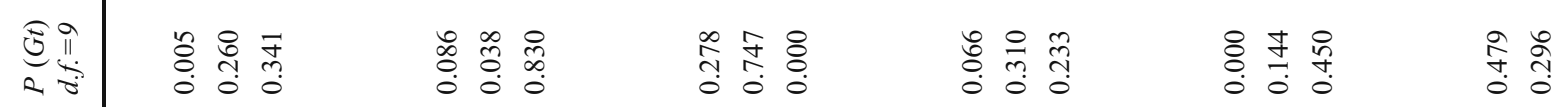

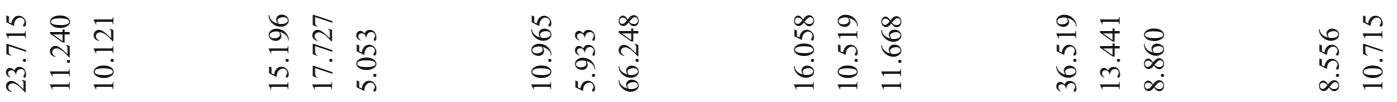

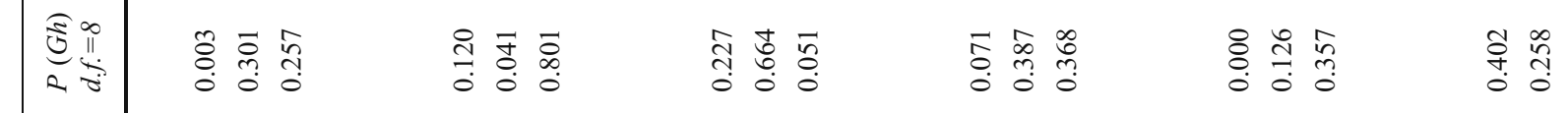

(1)

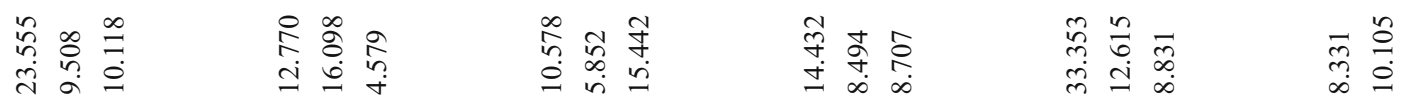

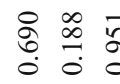

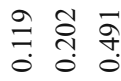

\begin{tabular}{lll}
4 & 0 & 8 \\
$n$ & \multirow{2}{*}{} & 0 \\
0 & 0 & 0
\end{tabular}

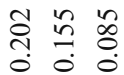

$\begin{array}{lll}n & n & t \\ \hat{0} & n & 0 \\ 0 & 0 & 0\end{array}$

$\begin{array}{ll}n & n \\ \hat{n} & ? \\ 0 & 0\end{array}$

8
$\stackrel{0}{0}$
$\stackrel{0}{-}$

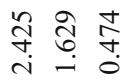

$\begin{array}{lll}n & \overline{0} & 0 \\ \infty & \infty \\ m & 0 & 0 \\ 0 & 0 & 0\end{array}$

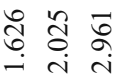

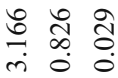

$\begin{array}{ll}\text { तิ } & 0 \\ 0 & 0 \\ 0 & 0\end{array}$

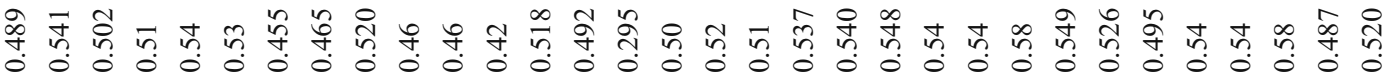

$\cong \cong$

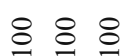

$\circ \circ \circ$

¿

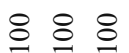

$\cong 8$

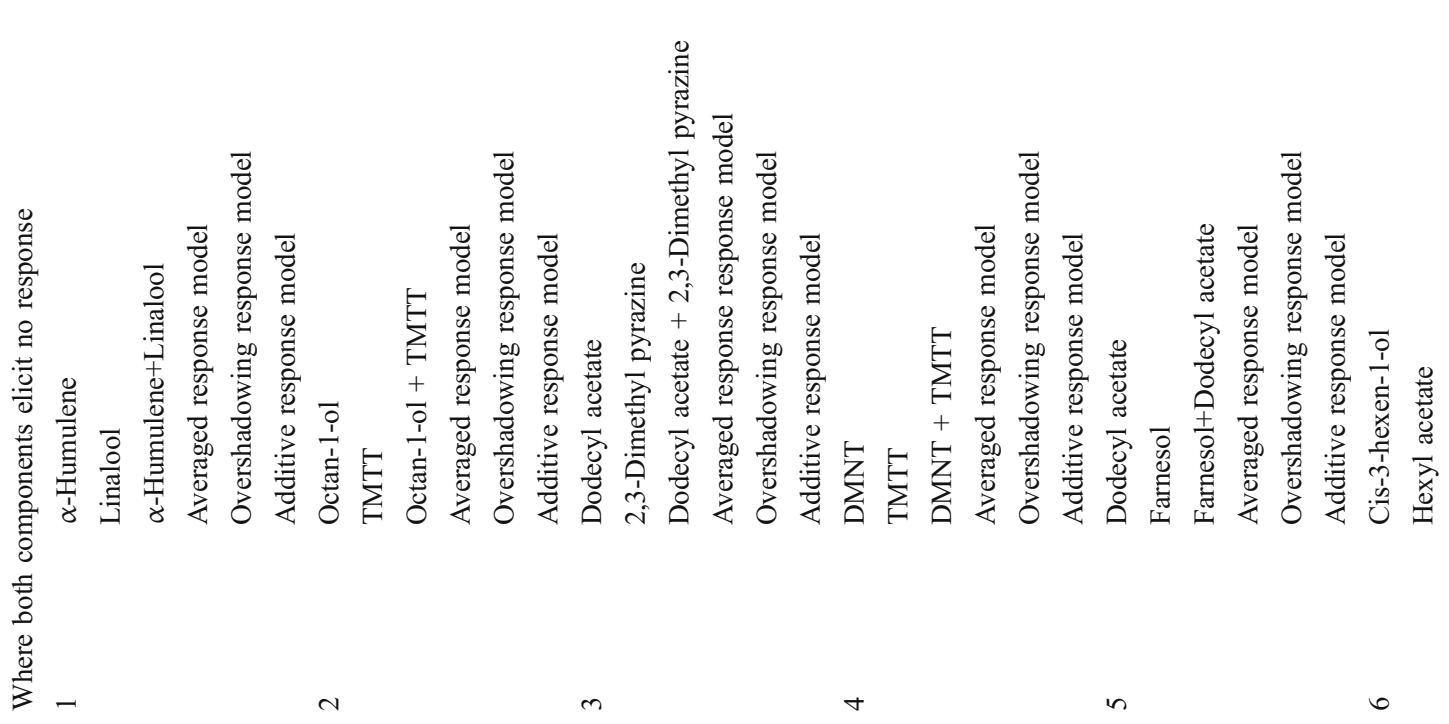




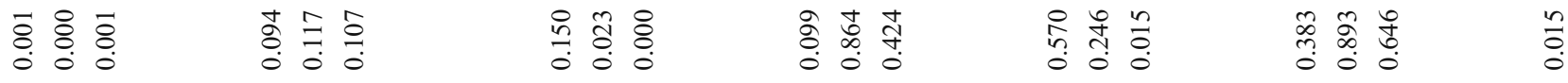

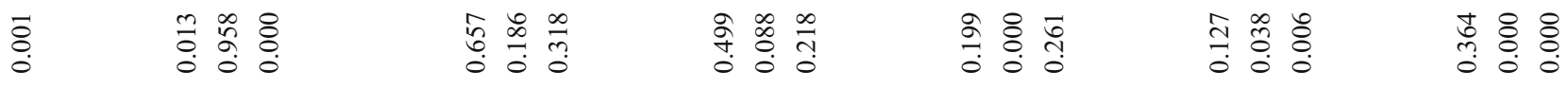

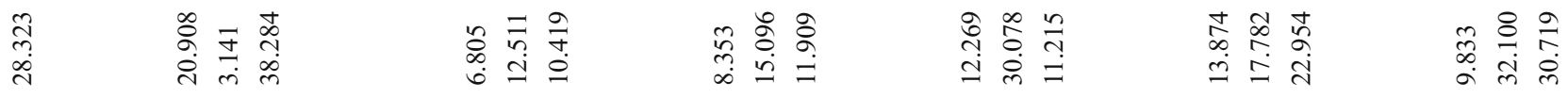

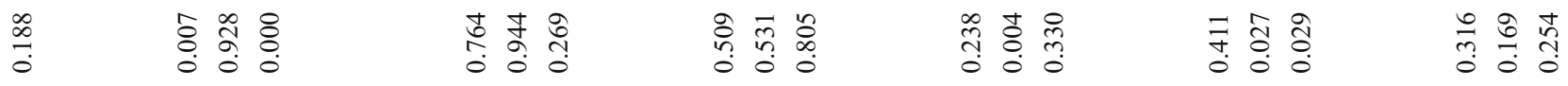

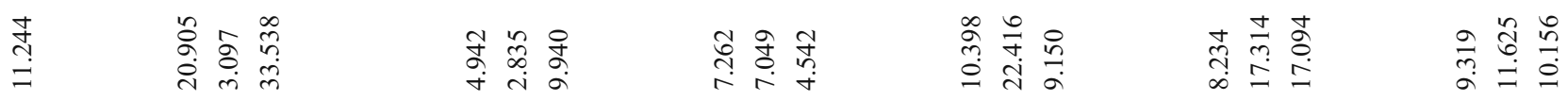

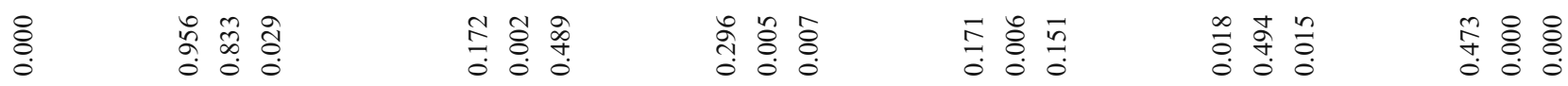

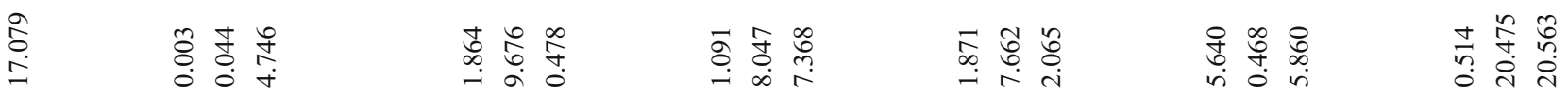

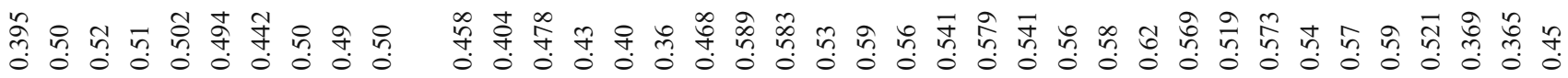

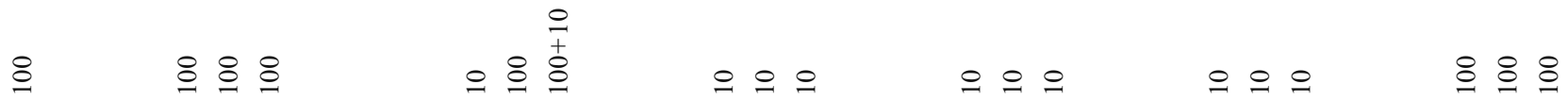

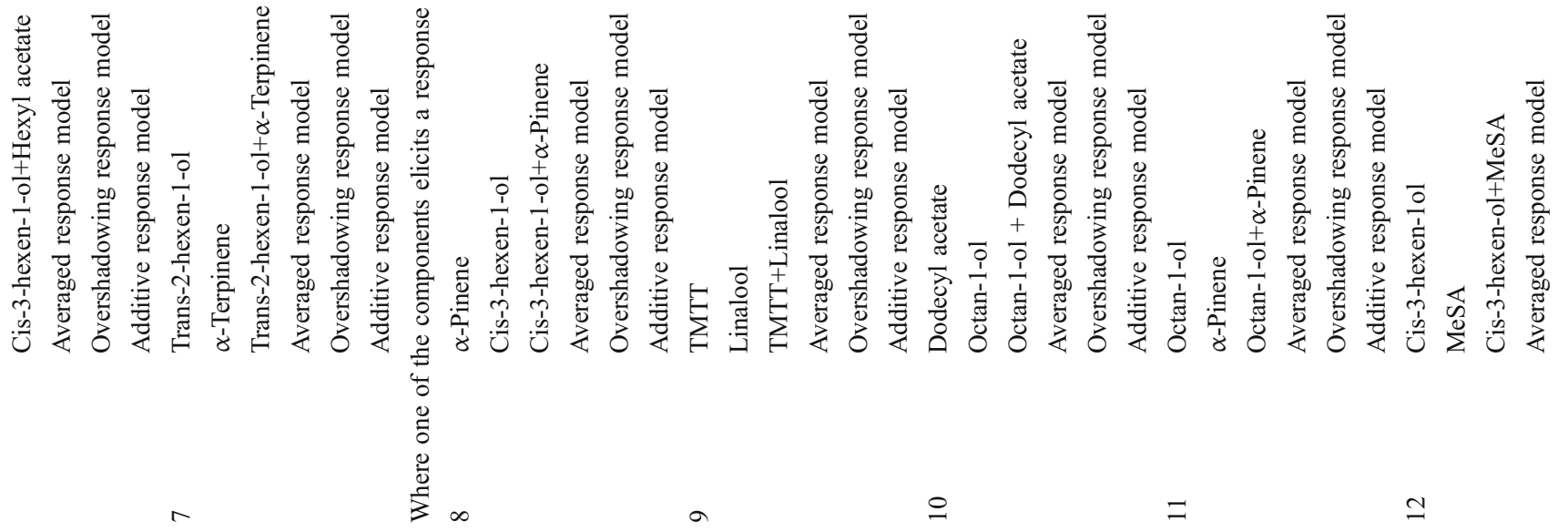




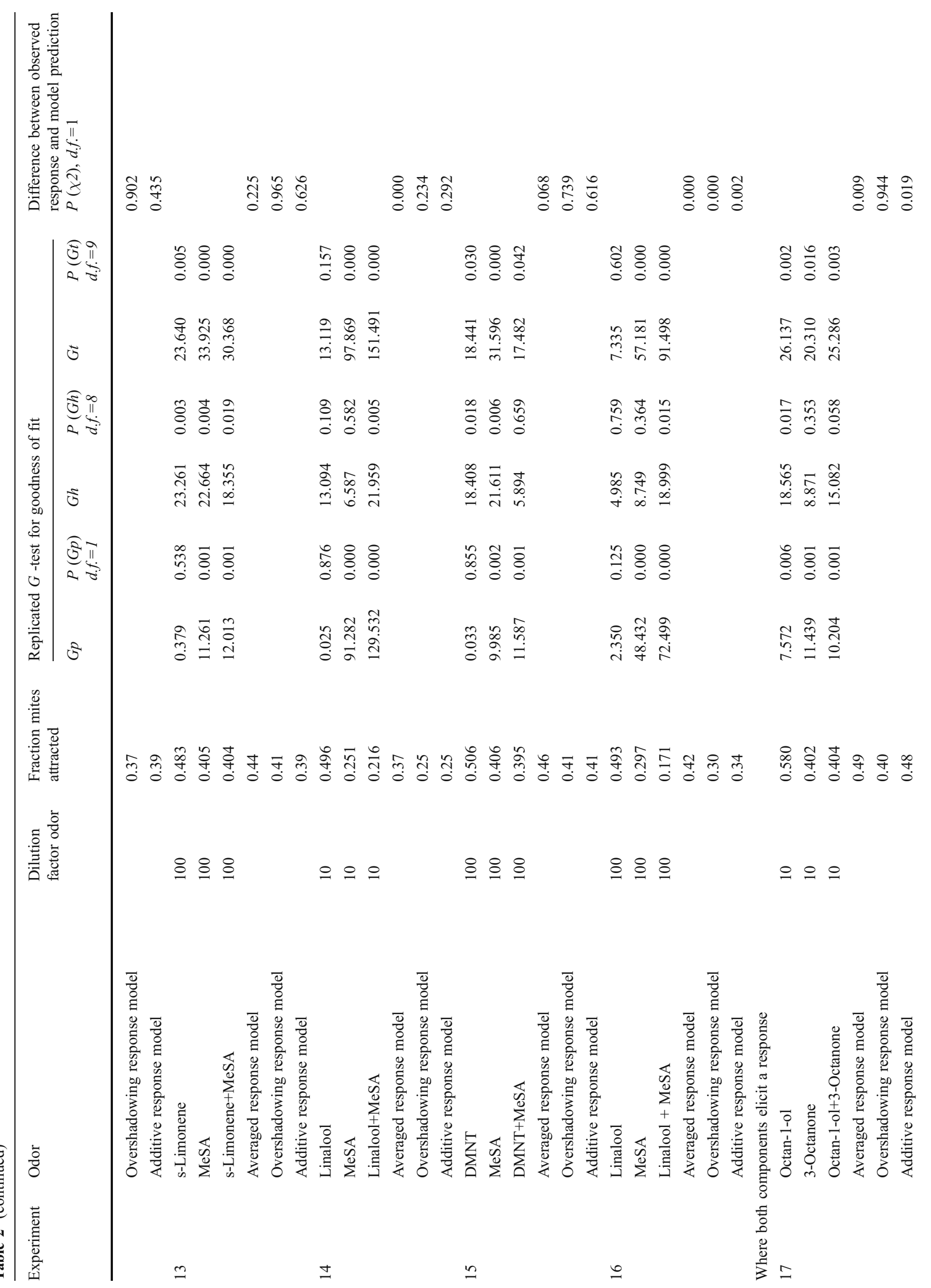




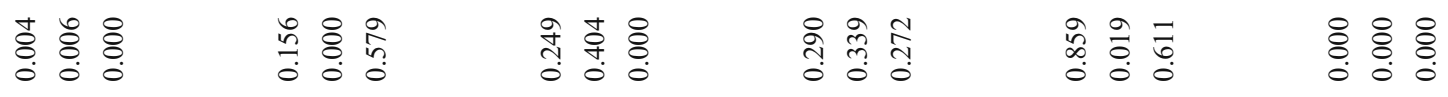

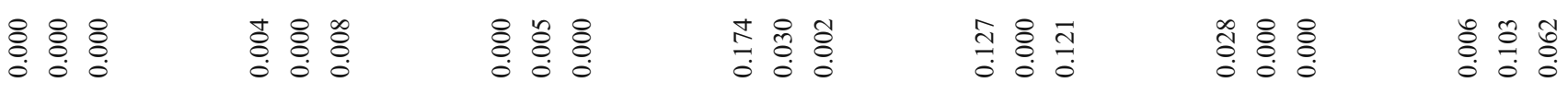

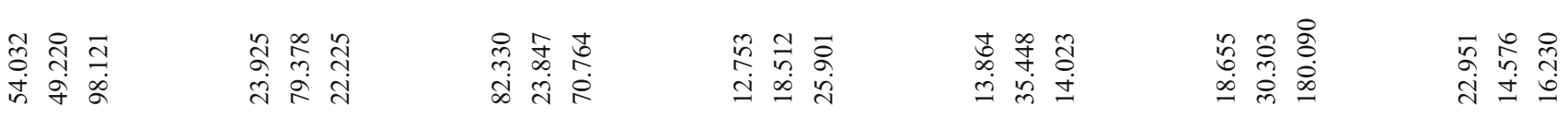

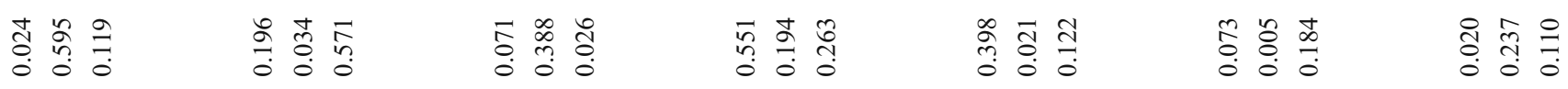

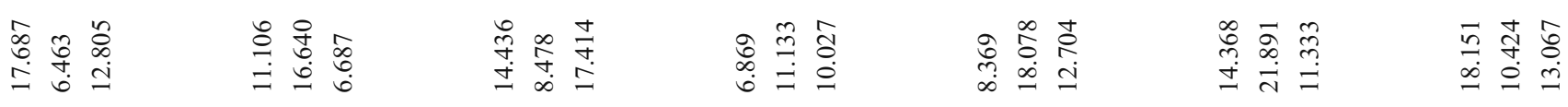

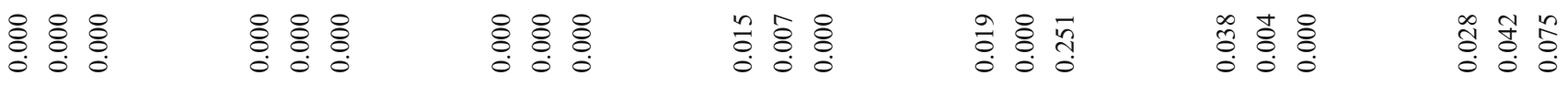

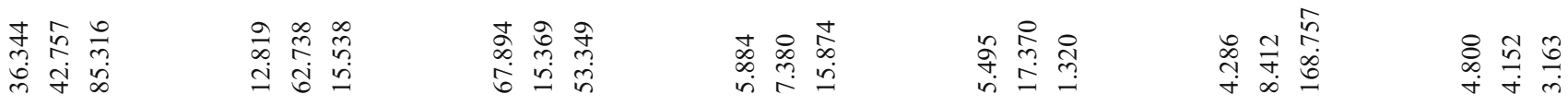

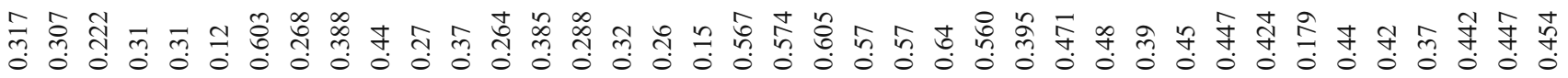

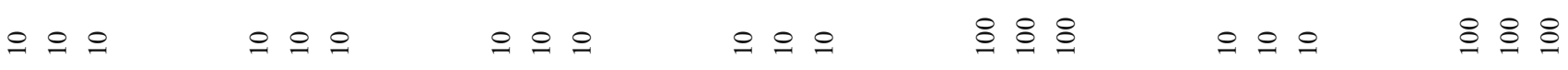

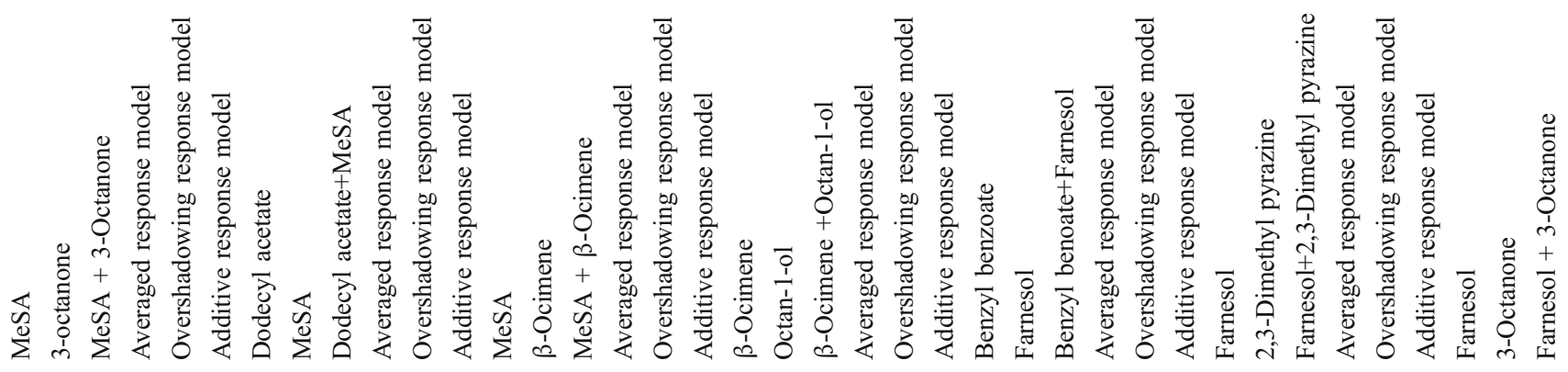

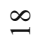

2

구

$\overline{4}$

ส

ก

ম 


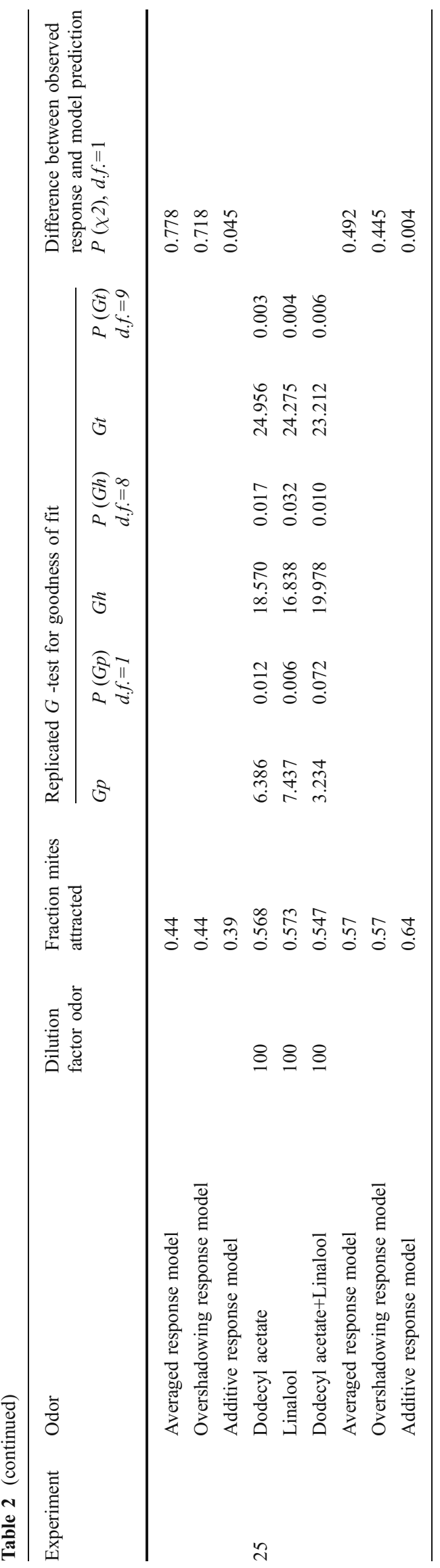

component that elicited the strongest response, which was most obvious in experiment 17 (octan-1-ol and 3-octanone) and 20 (MeSA and $\beta$-ocimene) but this also applies to experiment 21 ( $\beta$-ocimene and octan-1-ol), 24 (farnesol + 3-octanone), and 25 (dodecyl acetate and linalool). The additive response model accurately predicts the results obtained in experiment 19 (dodecyl acetate and MeSA), 20, 21, 24, and 25 (dodecyl acetate and linalool). Experiment 18 (MeSA + 3-octanone) revealed a weak additivity, which was significantly different from all three proposed models. There also are cases that are consistent with the additive response model experiment 19, 21, and 22 (benzyl benzoate and farnesol). On the other side of the spectrum, there was clear synergism in experiment 23 (farnesol and 2,3dimethyl pyrazine), which was significantly different from the predictions under all three proposed models.

Binary Mixtures with the Same Component Ratio at Different Concentrations Here, we examined the hypothesis that a function that describes the attraction to an odor mixture as a function of the attraction to its components at one concentration also applies to other concentrations of the mixture. For example, if a mixture of two compounds is as attractive as the sum of the attractiveness of its components, we asked if this relation holds over a range of concentrations where the two components occur in the same ratio.

Dose response curves for the response to binary mixtures and the response to their components were constructed (Fig. 2). Apart from propionic acid, none of the odors elicited a significant response at the lowest concentration $(1000 \times$ diluted). Since the individual components hardly elicited a response by the $P$. persimilis at this low concentration (van Wijk et al., 2008), and since the binary mixtures also hardly elicited a response (except for octan-1ol + decan-1-ol), we only considered the three higher concentrations to test the null hypothesis. The null hypothesis was rejected in five (Fig. 2e to i) out of nine examined dose response curves of binary mixtures and their components.

In two experiments in which the null hypothesis was not rejected, the response elicited by one component overshadowed the response elicited by the other at all concentrations (Fig. 2a and b). Hence, the possibility that $\alpha$-pinene was not perceived cannot be excluded (Fig. 2b). A mixture of two equally attractive components was not more attractive than either of its components (at all concentrations tested). Figure $2 \mathrm{~d}$ shows a mixture of two compounds that were neither attractive nor repellent at any concentration. At the two highest concentrations, i.e. pure and $10 \times$ dilution, the response to the mixture was not significantly different from the response to its components. At the $100 \times$ 


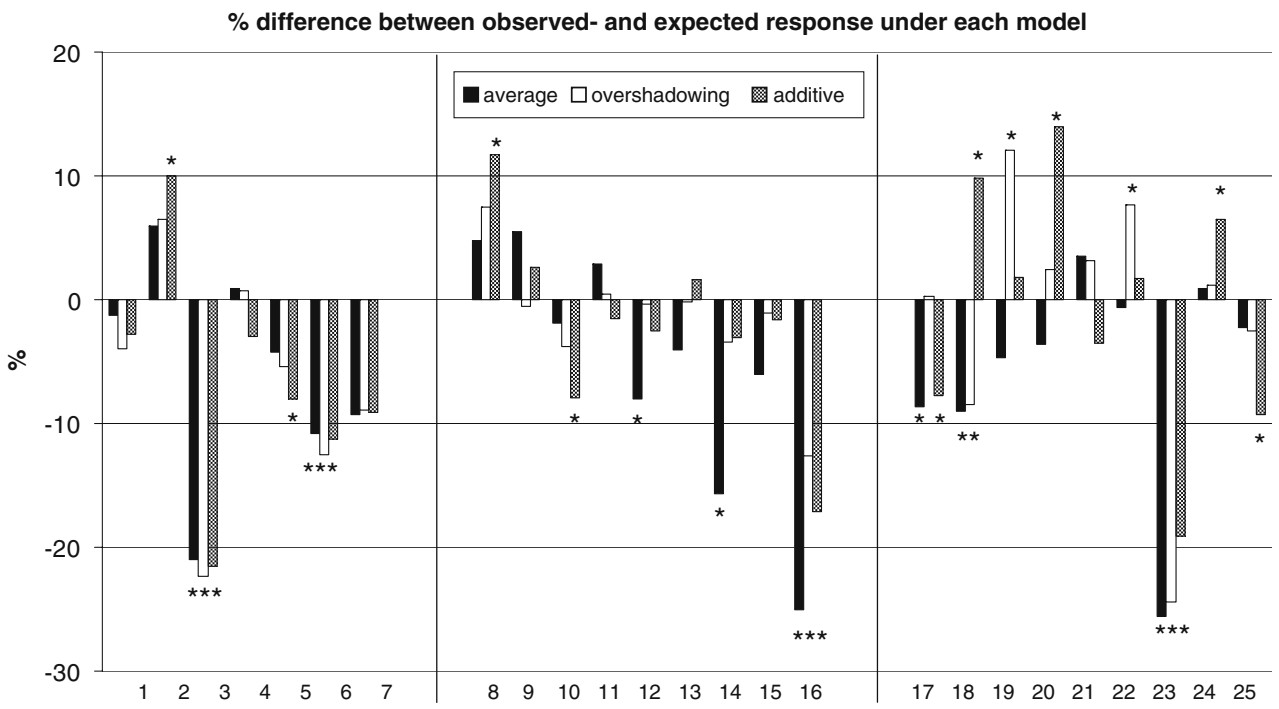

Fig. 1 Behavioral responses by Phytoseiulus persimilis to various odors. Below each group of three bars is the reference number of the experiment (also present in Table 2). Depicted is, for each experiment, the difference between the observed attraction $(N=225$ mites divided over 9 replicate choice tests) and predicted attraction under the averaging, the overshadowing and the additive response model

dilution, this difference was significant $\left(F_{2}=4.72, P=\right.$ 0.026 ), however, the mixture was significantly attractive $\left(G_{p}{ }^{*}\right)$ only at this dilution level while it tended to become significant at the $10 \times$ dilution $\left(P\left(G_{p}\right)=0.055\right)$. Hence, this is an example where a mixture of two components that elicited no response when presented individually, triggered significant attraction when offered in combination. Although statistical significance for the difference between the mixture and its components was reached only at the $100 \times$ dilution, this result does not violate the null hypothesis tested here, as the qualitative contribution of each of the mixture's components to the response of the mites was the same at all concentrations.

The graphs depicted in Fig. 2e to i, all contain at least two points in the dose-response curve that require a different function to describe the attraction to the mixture as a function of the attraction to its components at different odor concentrations. Hence, we conclude that in five out of nine examined dose-response curves of binary mixtures of a constant component ratio, the relative contribution to the behavior elicited by each of the mixture's components varies with the odor concentration. Consistent with the results reported in Table 2 both components of the mixtures used in the dose-response experiments (Fig. 2) also do not appear to contribute equally to the response elicited by the mixtures. Sometimes the response to the mixture is very different from the response to both components. Figure $2 \mathrm{e}$ (100× dilution, 2,3-dimethyl pyrazine $\left[\left(G_{p}{ }^{\mathrm{ns}}, G_{h}{ }^{\mathrm{ns}}\right), \alpha-\right.$ terpinene $\left.\left.\left(G_{p}{ }^{*}, G_{h}{ }^{*}\right)\right]\right)$ shows an example of a mixture respectively. A * indicates a significant difference $\left(X_{d . f .=1}^{2} P<0.05\right)$ between the observed response and the response under the model. The results are divided in three blocks representing experiments with both components of the mixture not eliciting a response, one component eliciting a response and both components eliciting a response, respectively

consisting of a neutral and an attractive compound that together are repellent $\left(G_{p}{ }^{*}\right)$. Figure $2 \mathrm{f}(10 \times$ dilution: propionic acid $\left(G_{p}{ }^{*}\right)$ and octan-1-ol, $\left.\left(G_{p}{ }^{*}\right)\right)$ shows an example of two attractive compounds that together are repellent $\left(G^{*}\right)$.

\section{Discussion}

Models based on neurophysiological principles have provided interesting insights in olfaction (Cleland and Linster 2005) and ideally are used to predict the response to odor mixtures. However, the neurophysiology of olfaction in organisms like $P$. persimilis is too poorly understood to construct models of olfactory information processing that incorporate morphological traits and physiological processes. This is why we used phenomenological models to test underlying general principles of information processing as they become apparent from behavioral responses.

The additive response model was based on the assumption that odors presented as individual compounds or as part of mixtures always elicit the same response. This requires that these odors are perceived strictly as elemental objects, and that each recognized object always triggers the same response. The responses to each compound are assumed to sum up to a response towards a mixture of these compounds. In the majority of mixtures studied (13 out of 25), the model prediction was significantly different from the observed results. This is consistent with results of 
(AB) $\sim$ octan-1-ol + methyl salicylate

a (A) -r - octan-1-ol

(B) - - - - - methyl salicylate

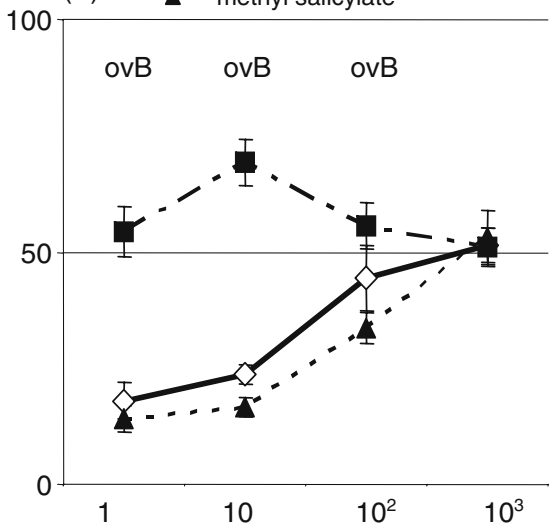

$(\mathrm{AB}) \longrightarrow$ methyl salicylate $+\alpha$-pinene

b (A) - - methyl salicylate

(B) - - $\Delta$ - - $\alpha$-pinene

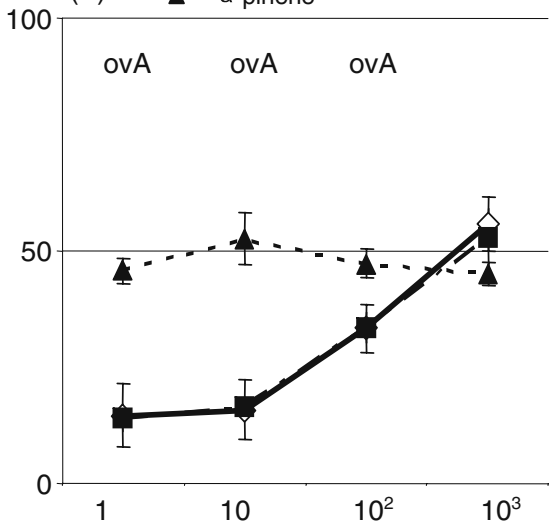

$(A B) \longrightarrow$ decan-1-ol + octan-1-ol

(A) -r - decan-1-ol

C (B) - - - - - octan-1-ol

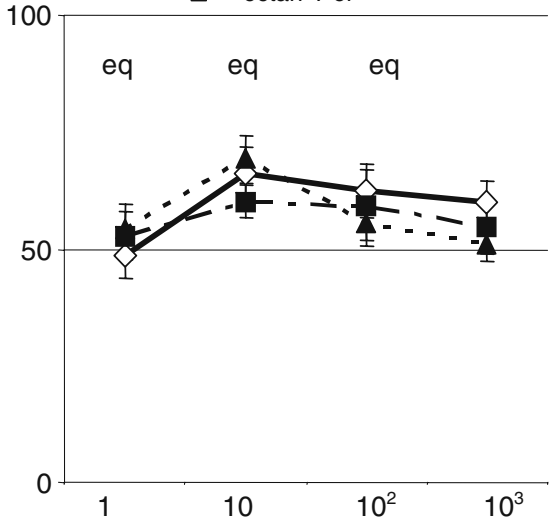

(AB) $\sim$ linalool + a-humulene

d (A) - - linalool

(B) - - $\Delta--\alpha$-humulene

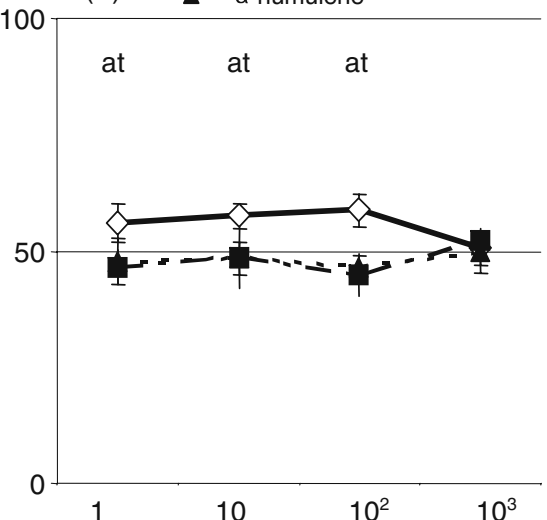

(AB) $\longrightarrow$ 2,3-dimethyl pyrazine $+\alpha$-terpinene

(A) - -2,3-dimethyl pyrazine

(B) - - - - a-terpinene

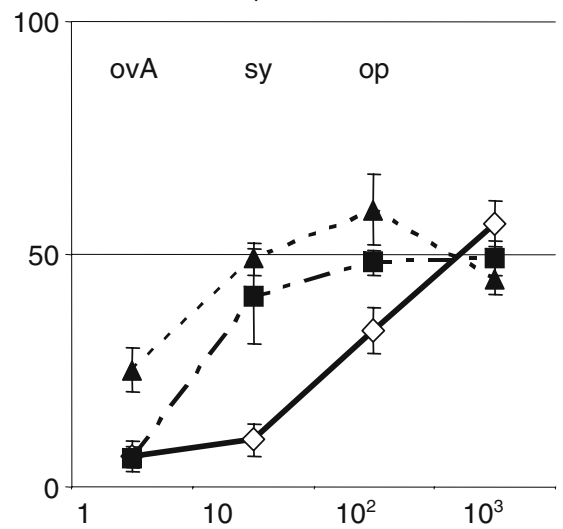

(AB) $\sim$ propionic acid + octan-1-ol

f (A) - - - propionic acid

(B) - - - - - octan-1-ol

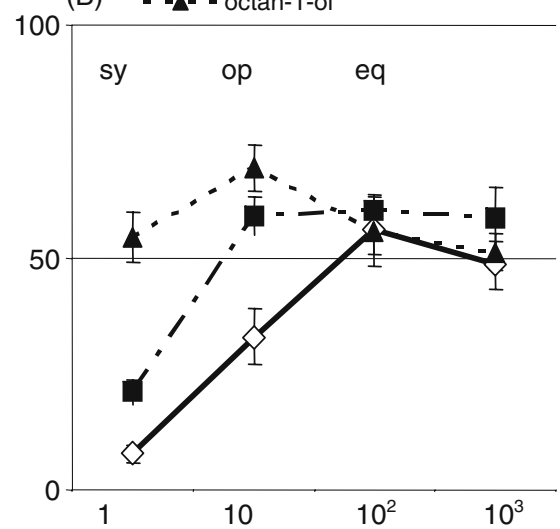

(AB) $\sim$ methyl salicylate+ linalool

g (A) - - methyl salicylate

(B) - - - - - linalool

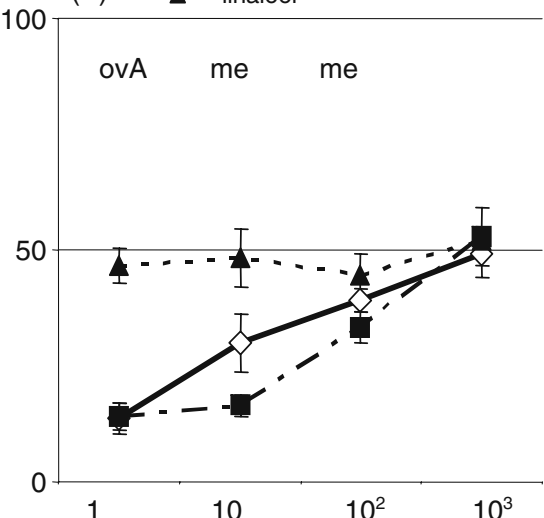

(AB) $\sim$ 3-octanone $+\alpha$-terpinene

h (A) - - 3-octanone

(B) - - $\mathbf{\Delta -}$ - $\alpha$-terpinene

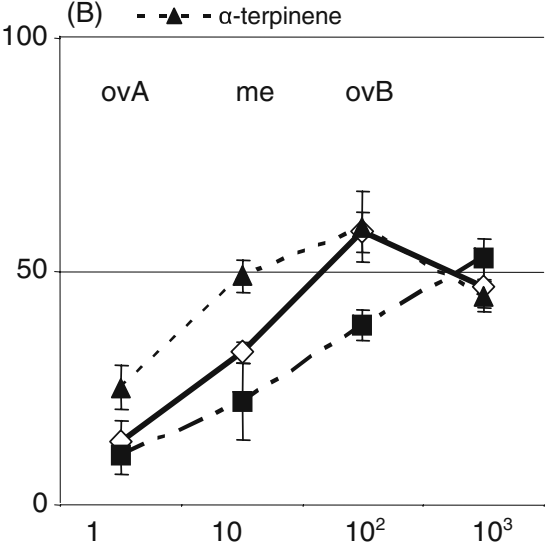

(AB) $\sim$ - -ocimene + TMTT

(A) - - $-\beta$-ocimene

i (B) - - - - - TMTT

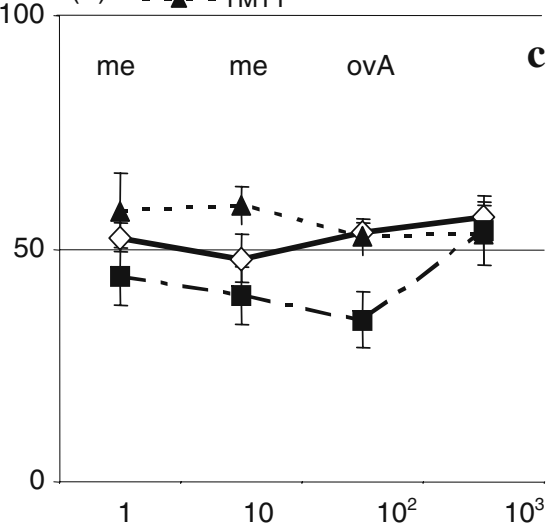

Fig. 2 The dose response relation of binary mixtures and their components. The experiments were conducted to assess if a function which describes the response of Phytoseiulus persimilis to a binary odor mixture as a function of the response to its components at one concentration also describes the response to the mixture at a different concentration. The $\mathrm{y}$-axis represents the attraction of $P$. persimilis to the odor $(N=120$ mites divided over 6 replicates $=100 \%)$, the $\mathrm{x}$-axis represents the four odor concentrations in decreasing sequence (pure, $10 \times, 100 \times$ and $1000 \times$-diluted in hexane). The lowest concentration was omitted from the analysis as the mites hardly responded to the mixture. Above each odor concentration is an abbreviation which qualitatively describes the response to the odor mixture as a function of the response to its components. Abbreviations: ovA/ovB: overshadowing by compound A or B, eq: equal to the mixture's components, me: mean, sy: synergism, op: opposite of its components, at: a mixture of neutral compounds which is attractive, TMTT: $(E, E)$ 4,8,12-trimethyl-1,3,7,11-tridecatetraene 
studies in spiny lobsters (Lynn et al., 1994; Derby et al., 1996), beetles (Thiery and Visser, 1986), and humans (Schiet and Cain, 1990; Laing et al., 1994) where the response to odor mixtures also was found to be different from the additive response to their components. We conclude that in the majority of the assessed mixtures, $P$. persimilis does not respond to components in odor mixtures as if each of these components is experienced in isolation.

The overshadowing response model is based on the assumption that a component that elicits the strongest response suppresses the detection of or the response to all other components in the odor mixture. This model was best applicable to the specific situation where only one of the mixture's components elicited a response. If both components elicited a response, it fared much more poorly, however. We conclude that the response to an odor mixture usually does not result from absolute overshadowing by the mixture's component that elicits the strongest response.

In its assumption that all components equally contribute to the response elicited by the mixture, the averaged response model retains a key feature of the elemental perception of odors. On the other hand, the contribution of each of the mixture's components to the elicited response is reduced by a factor equal to the number of other components in the mixture. This latter assumption states clearly that each component of an odor mixture affects the perception of or the response to all other components that are part of the mixture. The predicted response under the overshadowing and the averaged response model were significantly different from the observed response in respectively 8 and 9 out of 25 mixtures examined. We conclude that these two models, which assume that components of odor mixtures affect each other's perception, explain the observed response better than the additive model, which assumes an elemental perception of odor mixtures.

Our results suggest that there is no simple rule that will predict accurately the response of $P$. persimilis to binary mixtures as a function of the response to their components. For the simple binary mixtures tested here, the model that predicts the responses to mixtures best still fails to explain $32 \%$ of the observed responses. Although the three selected models together span a large part of the possible response spectrum we found that the observed response was significantly different from all three models in $20 \%$ of the mixtures assayed.

If we consider the results of both the experiments that tested model predictions and the dose response experiments, we find almost all possible interactions between the components in odor mixtures. There are examples of overshadowing, averaging, synergies, and even a case of attractive components that became repellent when offered in a mixture. There were components of mixtures that in isolation elicited no response, whereas they clearly affected the response elicited by mixtures they were part of. Furthermore, mixtures of the same two components at a constant concentration ratio gave - in the majority of the dose response curves assessed-rise to different interactions at different concentrations (Fig. 2). We conclude that the effect that different components in mixtures exert on the mite's response varies both with component identity and odor concentration. Consequently, knowledge about the repellence or the attractiveness of a specific odor has a limited predictive or explanatory value if this information is used in the context of the response that odor mixtures elicit in $P$. persimilis.

The response to some mixtures was so different from the response elicited by their components that they were probably perceived as something quite different from their components. Some species appear to perceive binary odor mixtures as elemental objects whereas, depending on the combination of odors in the mixture, binary mixtures appear to possess more synthetic properties in other species. Humans, for example, perceive the components of binary mixtures, while they fail to do so in mixtures with a complexity of three to four components (Laing and Francis, 1989; Livermore and Laing, 1996; Marshall et al., 2006). Binary mixtures appear to possess a varying degree of synthetic properties in other species such as rabbits (Coureaud et al., 2009), rats (Staubli et al., 1987; Linster and Smith, 1999; Wiltrout et al., 2003), and slugs (Hopfield and Gelperin, 1989; Sekiguchi et al., 1999).

Phytoseiulus persimilis is well known to acquire a preference for the odor of spider-mite-infested plants over the odor of uninfested plants. However, more remarkably, this predatory mite also learns to prefer odor from uninfested plants if this is associated with food (Drukker et al., 2000; van Wijk et al., 2008). If, in contrast to the results reported here, olfaction were strictly elemental, the mites could in theory associate each of the detectable components in an odor mixture with the presence of their prey. Phytoseiulus persimilis has been reported to acquire a preference for MeSA after it has been given the opportunity to associate MeSA containing plant odors with prey (de Boer and Dicke, 2004a), while other components of foodassociated odors do not appear to be associated with prey (van Wijk et al., 2008). Parasitoids and bees also behaviorally generalize their conditioned response from a mixture to a small number of its components, while they do not generalize this response to other detectable components in the mixture (Meiners et al., 2003; Reinhard et al., 2010). Other arthropods may not generalize their response to any of a mixture's components. The black bean aphid is repelled by nine host compounds, while a mixture of these repellents is an attractant (Webster et al., 2010). Similarly, the moth Manduca sexta responds only to a full floral odor blend and not to its components (Riffell et al., 2009). 
There is evidence that representations of odors become more distinct from their components with increasing mixture complexity and with the degree of similarity of the mixture's components. Measurements of the odor induced activity in second order neurons in the olfactory pathway of zebrafish have revealed that binary mixtures of pure odorants are often dominated by the responses induced by one of the components, while complex mixtures of food extracts that have many components in common are more distinct from their components (Tabor et al., 2004). Rats perceive mixtures of similar compounds as dissimilar from their components, while mixtures of dissimilar compounds are perceived as similar to their components (Wiltrout et al., 2003). In our experiments using simple binary mixtures, the mites responded to some mixtures as if they were odors distinct from their components. With increasing mixture complexity, there are more ways for components of odor mixtures to affect each others perception, thereby facilitating the mixtures distinctness from its components. This may well explain why the predatory mites do not generalize their response from the highly attractive odor of a spider-mite infested plant to most spider-mite induced components (van Wijk et al., 2008).

Open Access This article is distributed under the terms of the Creative Commons Attribution Noncommercial License which permits any noncommercial use, distribution, and reproduction in any medium, provided the original author(s) and source are credited.

\section{References}

Bolland, H. R., Gutierrez, J., and Flechtmann, C. H. W. 1998. World Catalogue of the Spider Mite Family. Leiden, The Netherlands, Brill.

Cleland, T. A., and Linster, C. 2005. Computation in the olfactory system. Chem. Senses. 30:801-813.

Coureaud, G., Hamdani, Y., SchaAl, B., and Thomas-Danguin, T. 2009. Elemental and configural processing of odour mixtures in the newborn rabbi t. J. Exp. Biol. 212:2525-2531.

DE BOER, J. G., and DiCKE, M. 2004a. Experience with methyl salicylate affects behavioural responses of a predatory mite to blends of herbivore-induced plant volatiles. Entomol. Exp. Appl. 110:181-189.

DE BOER, J. G., and DiCKe, M. 2004b. The role of methyl salicylate in prey searching behavior of the predatory mite Phytoseiulus persimilis. J. Chem. Ecol. 30:255-271.

Derby, C. D., Hutson, M., Livermore, B. A., and LynN, W. H. 1996. Generalization among related complex odorant mixtures and their components: Analysis of olfactory perception in the spiny lobster. Physiol. Behav. 60:87-95.

Dicke, M., and DiJKman, H. 1992. Induced defense in detached uninfested plant-leaves: Effects on behavior of herbivores and their predators. Oecologia 91:554-560.

Dicke, M., Van Beek, T. A., Posthumus, M. A., Bendom, N., Van BokHOVEN, H., and De GroOT, A. E. 1990. Isolation and identification of volatile kairomone that affects acarine predator- prey interactions: Involvement of host plant in its production. $J$. Chem. Ecol. 16:381-396.

Dicke, M, Takabayashi, J., Posthumus, M. A., Schutte, C., and KRIPS, O. E. 1998. Plant-Phytoseiid interactions mediated by herbivore-induced plant volatiles: variation in production of cues and in responses of predatory mites. Exp. Appl. Acarol. 22:311-333.

DrukKer, B., Bruin, J., JaCobs, G., KroON, A., and SABelis, M. W. 2000. How predatory mites learn to cope with variability in volatile plant signals in the environment of their herbivorous prey. Exp. Appl. Acarol. 24:881-895.

HopFIELD, J. F., and GELPERIN, A. 1989. Differential conditioning to a compound stimulus and its components in the terrestrial mollusc Limax maximus. Behav. Neurosci. 103:329-333.

Kappers, I. F., Aharoni, A., Van Herpen, T., Luckerhoff, L. L. P., DiCKE, M., and BOUWMEESTER, H. J. 2005. Genetic engineering of terpenoid metabolism attracts, bodyguards to Arabidopsis. Science 309:2070-2072.

KAY, L. M., and STOPFER, M. 2006. Information processing in the olfactory systems of insects and vertebrates. Semin. Cell Dev. Biol. 17:433-442.

LAING, D. G., and Francis, G. W. 1989. The capacity of humans to identify odors in mixtures. Physiol. Behav. 46:809-814.

LAING, D. G., EdDY, A., and BeST, D. J. 1994. Perceptual characteristics of binary, trinary, and quaternary odor mixtures consisting of unpleasant constituents. Physiol. Behav. 56:81-93.

Linster, C., and SMITH, B. H. 1999. Generalization between binary odor mixtures and their components in the rat. Physiol. Behav. 66:701-707.

LIVERMORE, A., and LAING, D. G. 1996. Influence of training and experience on the perception of multicomponent odor mixtures. J. Exp. Psychol. Human. 22:267-277.

Lynn, W. H., Meyer, E. A., Peppiatt, C. E., and Derby, C. D. 1994. Perception of odor mixtures by the spiny lobster Panulirus argus. Chem. Senses 19:331-347.

Marshall, L. K., Laing, D. G., JinKs, A. L., and Hutchinson, I. 2006. The capacity of humans to identify components in complex odor-taste mixtures. Chem. Senses 31:539-545.

MeInERS, T., WÄCKERS, F., and LEWIS, W. J. 2003. Associative learning of complex odours in parasitoid host location. Chem. Senses 28:231-236.

OKA, Y., OMURA, M., KATAOKA, H., and TOUHARA, K. 2004. Olfactory receptor antagonism between odorants. EMBO J. 23:120-126.

Reinhard, J., Sinclair, M., SRINIVASAN, M. V., and Claudianos, C. 2010. Honeybees learn odour mixtures via a selection of key odorants. PLoS ONE 5(2):e9110. doi:10.1371/journal. pone. 0009110

Riffell, J. A., Lei, H., Christensen, T. A., and Hildebrand, J. G. 2009. Characterization and coding of behaviorally significant odor mixtures. Curr. Biol. 19:335-340.

Rospars, J. P., LANSKY, P., ChapUt, M., and DUChaMP-VIRET, P. 2008. Competitive and noncompetitive odorant interactions in the early neural coding of odorant mixtures. J. Neurosci. 28:2659-2666.

SABelis, M. W., and VAN DER BAAN, H. E. 1983. Location of distant spider mite colonies by Phytoseiid predators: Demonstration of specific kairomones emitted by Tetranychus urticae and Panonychus ulmi. Exp. Appl. Acarol. 33:303-314.

Sabelis, M. W., VermaAt, J. E., and Groeneveld, A. 1984. Arrestment responses of the predatory mite, Phytoseiulus persimilis, to steep odour gradients of a kairomone. Physiol. Entomol. 9:437-446.

Sabelis, M. W., Janssen, A., Pallini, A., Venzon, M., Bruin, J., Drukker, B., and SCUTAREANU, P. 1999. Behavioural Responses of Predatory and Herbivorous Arthropods to Induced Plant Volatiles: From Evolutionary Ecology to Agricultural Applications. APS Press, The American Phytopathological Society, St. Paul, Minnesota. 
SChIET, F. T., and CAIN, W. S. 1990. Odor intensity of mixed and unmixed stimuli under environmentally realistic conditions. Perception 19:123-132.

SCHRÖDER, R., and HILKER, M. 2008. The relevance of background odor in resource location by insects: A behavioral approach. Bioscience 58:308-316.

Sekiguchi, T., Suzuki, H., Yamada, A., and Kimura, T. 1999. Aversive conditioning to a compound odor stimulus and its components in a terrestrial mollusc. Zool. Sci. 16:879-883.

Staubli, U., Fraser, D., Faraday, R., and LynCH, G. 1987. Olfaction and the "data" memory system in rats. Behav. Neurosci. 101:757-765.

SOKAL, R. R., and RoHLF, F. J. 1995. Biometry. W. H. Freedman and Company, New York.

TABOR, R., YAKSI, E., WeISLOGEL, J. M., and FrIEDRICH, R. W. 2004. Processing of odor mixtures in the zebrafish olfactory bulb. $J$. Neurosci. 24:6611-6620.

THIERY, D., and VISSER, J. H. 1986. Masking of host plant odour in the olfactory orientation of the Colorado potato beetle Entomol. Exp. Appl. 41:165-172.

Van Den Boom, C. E. M., VAn BeeK, T. A., and Dicke, M. 2002. Attraction of Phytoseiulus persimilis (Acari : Phytoseiidae) towards volatiles from various Tetranychus urticae-infested plant species. Bull. Entomol. Res. 92:539-546.

Van Den Boom, C. E. M., Van Beek, T. A., Posthumus, M. A., De Groot, A., and DicKe, M. 2004. Qualitative and quantitative variation among volatile profiles induced by Tetranychus urticae feeding on plants from various families. J. Chem. Ecol. 30:69-89.

VAN WiJK, M., De Bruijn, P. J. A., and SABelis, M. W. 2008. Predator attraction to herbivore-induced plant odours is not a consequence of attraction to individual herbivore-induced plant volatiles. J. Chem. Ecol. 34:791-803.

VAN WiJK, M., WADMAN, W. J., and SABelis, M. W. 2006a. Gross morphology of the central nervous system of a phytoseiid mite. Exp. Appl. Acarol. 40:205-216.

VAN WiJK, M., Wadman, W. J., and Sabelis, M. W. $2006 \mathrm{~b}$. Morphology of the olfactory system in the predatory mite Phytoseiulus persimilis. Exp. Appl. Acarol. 40:217-229.

Webster, B., Bruce, T., PICKETt, J., and HARdie, J. 2010. Volatiles functioning as host cues in a blend become nonhost cues when presented alone to the black bean aphid. Anim. Behav. 79:451-457.

Wiltrout, C., Dogra, S., and Linster, C. 2003. Configurational and nonconfigurational interactions between odorants in binary mixtures. Behav. Neurosci. 117:236-245. 